\title{
Effect of Organizational Justice on Turnover Intention: Mediating Role of Employee Motivation
}

\author{
MUHAMMAD YOUNAS \\ IBMS, University of Agriculture Peshawar, Khyber Pakhtunkhwa \\ IMRAN SAEED \\ International Islamic University, Islamabad \\ GHAYYUR QADIR \\ Abdul Wali Khan University Mardan \\ ghayyurqadir@awkum.edu.pk \\ SAIF ULLAH KHAN \\ University of Peshawar
}

\begin{abstract}
Turnover is a substantial problem all over the world, in all the industries. The problem is further impairing to the performance of knowledge intensive industries such as pharmaceuticals. This study examined the effect of Organizational justice facets i.e. Procedural Justice, Distributive Justice and Interactional Justice on Turnover Intention. Based on a sample of 14lemployees from 19 Private sector pharmaceutical companies located in Peshawar. The results reveal that Procedural Justice and Distributive Justice have significant and constructive effect on Turnover Intention while of Interactional Justice had no statistically significant effect. The analysis also shows that Intrinsic and Extrinsic Motivation as mediating variables significant effect on relationship between Organizational and Turnover Intentions.
\end{abstract}

Keywords: Organizational justice, Procedural justice, Distributive justice, Interactional justice, Turnover intention, Intrinsic motivation, Extrinsic motivation

\section{Introduction}

Human resource in an organization is referred to as the most important asset of the organization because they have the potential to put their organization on the pathway of prosperity and growth. They are not just the people working in an organization but a broad combination of experience, attitudes, abilities, culture etc. Productivity and commitment of employees increases when they are kept motivated. Creating motivation at the same time, is not an easy task for managers to do because their environment has been increasingly complex in view of the globalization and multinational era having different cultures, believes, norms and expectation. This is also important in retaining employees and avoid turnover. Motivation can be either ways applied i.e. intrinsic motivation (goodwill, inner (psychological) satisfaction, respect, self-actualization, selfdetermination, intangible assets, commitment, social status and contacts etc.) and 
extrinsic motivation (reward, compensation (salary, remuneration), tangible assets, good work place environment etc.). The perceived injustice in organization by an employee arouses turnover intention and thus results in employee turnover that is the voluntary exit from organization. Employee observe stress and dissatisfaction at workplace caused by various factors like unjust exploitation, unjust environment, competence issues, integrity and respect, conflicts/relation with peer and supervisor, job security and lack of career prospects. These situations are sometime difficult to deal with from the organizational point of view as well as from the employees' perspective because defining and framing rules and regulations for every situation causing stress at work place is very difficult. A holistic approach from the perspective of organization based on strong ethical foundation is required to encapsulate the issues relating to motivation, employees' expectation, organizational justice and fairness at workplace.

Organizational justice was coined by Greenberg (1987) and defined as the individual's perception of fairness at workplace and the reaction he shows to it is Organizational justice. It is also referred to as the actions and decisions are morally right - defined according to religion, ethics, fairness and law. It is a general humans' nature that they are attentive to the justice in their everyday life (Gropanzano, 2009). Justice is operationalized in three dimensions: distributive justice, procedural justice and interactional justice. Distributive justice refers to the perceived fairness of the outcomes, procedural justice refers to the perceived fairness of the means used to determine those outcomes (Folger and Konovsky, 1989; Cropanzano and Greenberg, 1997), and interactional justice refers to the fairness of interpersonal treatment (Marti'nez-Tur et al., 2006). Many research studies have been conducted to find the effect of organizational justice on turnover intention, job satisfaction, and organizational citizenship behavior (Nadiri and Tanova, 2010; Allen and Meyer, 1996; Mathieu and Zajac, 1990; Tett and Meyer, 1993 Flint et al, 2012). Masterson and Taylor (1996) said that Employee perception of IJ predicts supervisory relate outcomes, also reported that $\mathrm{PJ}$ is perceived as organizational commitment while IJ is perceived as supervisor related outcomes that are resulting in intention towards turnover. The re-examination by Moorman (1991) supported Masterson and Taylor's study and concluded that PJ measures the fairness in organization policies and IJ measures the fairness of supervisory dealings. Equity theory and social exchange theory are the underpinning theories that are supporting the relationship of OJ and TI in organization.

The equity theory or Adam's motivation theory (1965) is based on the comparison of the perceived input to the output. Where one thinks that his efforts are not rewarded in accordance to the results and are also not equal to that of others (Peers), which may demotivate him and lead him toward absenteeism and TI. Social exchange theory is the cost and benefits ratio of an employee that he expects, thus he puts high efforts (high cost) and getting less benefits will create dissatisfaction at the job (Emerson, 1976). Aforementioned motivation in this study is supported by Self Determination Theory (SDT) which says that People having External Perceived Locus of Causality (EPLOC) to the extent they experience force from external environment like initiating, pressuring and threatening (coercing) their actions (un justice), whereas according to Internal Perceived Locus of Causality (IPLOC) individual perceives himself as the 
initiator and sustainer of his own actions. Similarly, people having high IPLOC feel selfdetermined as they feel their behavior caused by their own interests such as their choices, values and interests. Accordingly, people having EPLOC, their behaviors are controlled by the event, persons or force outside them. The IPLOC relates to intrinsic motivation and the EPLOC is related to extrinsic motivation. The difference between IM and EM is the core element of self-determination theory, which was emerged while studying behaviorism and conditioning, where in reward and punishment are the bases for behavior management. The SDT identifies three needs that achieve satisfaction that are Competence (excelling in what one do), Relatedness (linking) with others and Autonomy (being in control of one own life).Previous studies have examined the effect of OJ on different work outcomes and found significant (see literature review). Spatiality of this study is to find the mediational effect of motivation through Baren and Kenny 1986 and also through Kenny 2012 procedure. The objectives of the study is divided into two steps first of all finding the effect of Organizational Justice dimensions (PJ, DJ and IJ) on turnover intention (TI) separately secondly finding the mediational effect of Motivation diminutions (Intrinsic Motivation and Extrinsic Motivation) on relationship between organizational justice and turnover intention.

\section{Literature Review and Hypotheses}

\subsection{Organizational Justice}

Many scholars and researchers studied OJ since last 40 years that why employees face unjust environment like Owolabi in 2012 reported that in every organization, justice is very important because the implications of perceptions of injustice can impact job attitude and performance. Justice in organizations therefore comprises of issues such as perceptions of fair remuneration, equal opportunity right and personnel induction mechanism. Colquitt et al. (2001) conducted a research study on Justice at the millennium: a meta-analysis review of 25 years of organizational research stated that the earlier research studies evidently shows that work attitudes and behavior of employees are affected by organizational justice. James (1993) elaborated that organizational justice explains the perception of individuals regarding fair and just treatment encountered from an organization and the behavior they exhibit regarding their perceptions. Adams (1965) stated that fairness in workplace regarding perceptions of employees and their outcomes to that of subordinates also stated that the inequality in those outcomes in comparison with those of others in an organization which led to the individual's disappointment and will change their behavior and reluctant to perform well accordingly.

Justice, in the present study is ponders upon from three dimensions, i.e. Procedural justice, Distributive justice and Interactional justice. First one is Procedural Justice, Cropanzano and Greenberg, (1997) defined Procedural justice as a justice refers to the perceived fairness of the means used to determine those outcomes. Blader \& Tyler (2005) stated that faire procedures are better valued due to decision control and which result in instrumental postulation of fair outcomes; and those outcomes are communicated among them, that they are standing in the group and respectable. May and Brown (1994) suggested that when the outcomes are fair and just the employees feel himself in likable /desirable position so they can ultimately retain their positive attitude towards organization regarding the procedures the organization have, even the outcomes 
itself is not desirable. Leventhals (1980) stated in his theory regarding procedural justice is that procedures that are applied continuously having no bias, information accurately communicated, decision correcting mechanism applied, having ethical standards and find those with unfair treatment.

Thibaut and Walker (1975) demonstrated in their study that fairness is not the central concern of individuals regarding decision outcomes but also procedural fairness should be followed in making those decisions. Distributive justice refers to the individual's perception of the equity of the allocation of resources (Greenberg, 1990). Adams (1965) stated that the fairness of the outcomes allocation and is evaluated with equity in distribution of those outcomes known as Distributive justice. Cohen-Charash \& Spector, (2001) stated in their study that Distributive justice is the fairness of outcomes and predict that it mainly associates with affective (resentment), cognitive (perceptual distortion), and behavioral (withdrawal) that reactions is to the actual outcomes. Kacmar et al. (1999) argued that individuals feel inequity and they can change their behavior automatically or alter discrepancies and the employee think about withdrawal or some time withdraws from the current job they have. Further stated that if there is limited job opportunity available for an employee they cannot immediately withdraws the job but internally they experience psychological withdrawal rather than physical. And as a result they think about resigning from the position they have or having intention to quit. Alexander and Ruderman (1987) stated that the fairness in distribution is the direct cause of TI. In their study they have six organizational outcome variables; i.e. JS, TI, tension/stress, trust in management, conflict/harmony and supervisor evaluation. Out of six variables five of them showed considerable effects on justice but one variable i.e. tension/ stress having no effect on both PJ and DJ. Four out of five variable shows considerably effected by PJ rather than on DJ. Also showed that TI having stronger causal effect with DJ rather on PJ.

Cruceru and Macarescue (2009) stated that interactional justice is concerned about the persons' relation and interaction rather than any tangible reward. IT depends upon the organization leaders that how the decision are carried out in favorable conditions. How the supervisors treat their subordinates subject to their decisions and actions. Researcher found that effect of IJ is independent of individual's evaluation of fairness regarding outcomes received and also the allocation of those outcomes. They further argued that in subordinate and supervisor relations there exists a high degree of interactional justice (IJ) which reduces the likelihood of unproductive work behavior to occur. If IJ is perceived by a subordinate then he will feel annoyance toward the supervisor and the organization and will try to "even the score". An employee affected by IJ will have natural tendency of hostility toward the annoying one and may result in disadvantageous work behavior and thus reducing the effectiveness of organizational communication. Colquitt et al (2001) stated that interactional justice (IJ) in organizational justice is the simplest one to understand. How a person treat others. A person with interactional just behavior may share information accurately and don't use rude or cruel remarks. Similarly IJ is divided into two types that is informational justice where in an employee is truthful and provides sufficient justification when things go in undesirable way. The other type is interpersonal justice which is the extent of respect and dignity to 
treat others. Bais and Mong (1986) proposed that the third dimension of organizational justice is Interactional justice which is defined as the supervisor's applications of the rules for communicating fairness to their employees. They also stated that procedures lead to interactions that, intern lead to outcomes and emphasized the importance of separating the analysis of procedures from the interactions themselves.

\subsection{Effect of Organizational Justice dimensions (PJ, DJ and IJ) on Turnover Intention}

Khan et al. (2013) suggested that two of the justice dimensions (i.e. DJ and PJ) should associate with outcomes at work. When individuals perceived that the procedures used for reward distribution and the actual reward distribution are fair, they feel satisfied with their jobs and tend to reciprocate by demonstrating elevated levels of job involvement and reduced intentions to leave their organizations. Poon (2012) conducted a research study on DJ, PJ, Effective Commitment, and TI (A Mediation- Moderation Framework) Journal of Applied Social Psychology in Malaysia, and resulted that turnover intention and distributive justice having negative relationship. Moderation mediation model was used in which procedural justice was used as moderating variable and affective commitment was used as mediating variable. Fatt et al. (2010) formulated that employees will be more satisfied when they feel that the received outcomes are allocated fairly; they will be more committed and retain the position in the company for long, oppose aggressive job offerings, will not aggressively searching for other job and give suggestions to others about the company as a batter place for work. Brashear et al. (2005) conducted a research study, the effect of control, trust, and justice on salesperson turnover in USA a study of 240 business-to-business sales people and finds that turnover intention is the significant and direct criterion of distributive justice. Colquitt et al. (2001) stated in their study that perception of treating fairly in organization is highly effecting satisfaction at job and organizational commitment and decrease in turnover intention and increase in organizational citizenship behavior. Lee (2000) stated in his study that the quality of interpersonal treatment got by the employees of an organization from their supervisors, which effect the subsequent perception of employees regarding procedural justice, distributive justice, job satisfaction, organizational commitment and turnover intention. McFarlin and Sweeney (1992) argued in their research study and stated that procedural justice was found to be a strongest predictor of TI rather than DJ.

$\mathrm{H}_{0}$ : Procedural justice has no significant effect on employee Turnover Intention.

$\mathrm{H}_{1}$ : Procedural justice has a significant effect on employee Turnover Intention.

$\mathrm{H}_{0}$ : Distributive justice has no significant effect on employee Turnover Intention.

$\mathrm{H}_{1}$ : Distributive justice has a significant effect on employee Turnover Intention.

$\mathrm{H}_{0}$ : Interactional justice has no significant effect on employee Turnover Intention. $\mathrm{H}_{1}$ : Interactional justice has a significant effect on employee Turnover Intention.

\subsection{Employee Motivation: A Self Determination Theory Perspective}

Aforementioned motivation in this study is supported by Self Determination Theory (SDT) which says that People having External Perceived Locus of Causality (EPLOC) to the extent they experience force from external environment like initiating, pressuring and threatening (coercing) their actions (un justice), whereas according to Internal Perceived Locus of Causality (IPLOC) individual perceives himself as the 
initiator and sustainer of his own actions. Similarly people having high IPLOC feel selfdetermined as they feel their behavior caused by their own interests such as their choices, values and interests. Accordingly, people having EPLOC, their behaviors are controlled by the event, persons or force outside them. The IPLOC relates to intrinsic motivation and the EPLOC is related to extrinsic motivation. The difference between IM and EM is the core element of self-determination theory, which was emerged while studying behaviorism and conditioning, where in reward and punishment are the bases for behavior management. The SDT identifies three needs that achieve satisfaction that are Competence (excelling in what one do), Relatedness (linking) with others and Autonomy (being in control of one own life). Dysvik and Kuvaas (2010) found that intrinsic motivation (IM) is the predictor of Turnover intention (TI). Further suggested that IM holds a substantial role to predict TI and also significant in relation. Similarly, this study has also established the relationship between the dimensions of work motivation (IM and EM) as a mediating variables and other variable of interest i.e. dimension of organizational justice and turnover intention. Zapata et al. (2009) formulated a study on PJ, IJ, and task performance; mediating role intrinsic motivation (IM), and found that both PJ and IJ have positive effect on IM. Cropanzano and Rupp (2003) gave conceptual base of the relationships between these variables can be traced back to Adam's (1963and 1965) Equity theory and the Porter and Lawler's (1968) model of work motivation and postulated that the relationships according to equity theory can be described as unfair outcomes e.g. pay status etc. giving an employee a motivational force to rectify the unfair occurrence to if they haven't feel pleasant with those outcomes, and ones behavioral actions that could be taken to decrease their level of performance and inputs. Bretz et al. (1994) suggested that diverse motivational forces affect job exploration and withdrawal. They further found that associated with various work and workplace environment (i.e. compensation, job satisfaction and organization policy) are all related to job search.

Keaveney and Nelson (1993) noted that intrinsic work motivational orientation frames an important buffer against stress on job. They also noted that job satisfaction is positively influenced by intrinsic motivation and turnover is negated. Moreover, study observed that work motivation originates emotional exhaustion and work satisfaction which directs intention toward turnover.Martin et al (1993) resulted that the individuals with negative mood persist shortly then individuals with positive mood, and presumed to maintain state of positive affection by taking both they argued that one potentially reacts to PJ and IJ devoted to be greater in intrinsic motivation. Katzell and Thompson (1990) stated that Work motivation is emerge as the area having increased organizational concern. Work motivation is the situation and processes that are responsible for arousing, directing and motivating the efforts in one's job. Tyagis (1990) found in a research study of insuring sales people argued that there is strongly unpleasant effect on external motivation regarding perceived unfair money and similarly unfair recognition had significantly negative effect on internal motivation of sales persons.Vroom (1964) suggested that by raising level coworker's motivation at work can increase work effectiveness. Various researches clearly support the view that holding the ability constant for most jobs; workers with high motivation 1 perform at highly significant rates 
rather than workers with demotivation. Mcgregor (1960) argued that sufficient reasons and empirical data is available suggesting that in the organizations' environmental conditions i.e. feedback system; reward system and task structures can have a considerable impact on individual level of motivation.

$\mathrm{H}_{0}$ : There is no mediation effect of Intrinsic Motivation on the relationship between Organizational justice and employee turnover intention.

$\mathrm{H}_{1}$ : There is mediation effect of Intrinsic Motivation on the relationship between Organizational justice and employee turnover intention.

$\mathrm{H}_{0}$ : There is no mediation effect of Extrinsic motivation on the relationship between organizational justice and employee turnover intention.

$\mathrm{H}_{1}$ : There is mediation effect of Extrinsic Motivation on the relationship between Organizational justice and employee turnover intention.

\section{Methodology}

According to Pakistan Pharmaceutical Manufacturing Association (PPMA), In Pakistan Pharma sector industry is amongst the fastest growing industry. In Khyber Pakhtunkhwa there are many pharmaceutical units in different regions and districts for our convenience those industries located in Hayatabad Industrial Estate were selected. In total there are 19 pharmaceutical units in Industrial Estate Peshawar, manufacturing different kinds of Pharma products and a total of 1132 Employees are associated with Pharma industry (DOL, 2013). The employees working in those pharmaceutical units/factories were considered as universe of the study. Numbers of human resource were selected as a sample from 19 pharmaceutical units was sufficient to address the objectives of the study. Keeping in mind the time and financial constraints, $17.13 \%$ makes round about 194 employees were selected as a sample from the entire universe of the study by using proportional allocation method (Cochran, 1977). Data were collected from the sampled respondents through questionnaire. It was structured, close ended and self-administered questionnaire. We distributed 194 questionnaires, out of which 152 responses were returned, 11 responses were eliminated through outlier analysis left with 141 round about $73 \%$ response rate. Most of the respondents were found reluctant to fill the questionnaires but we assured them full secrecy.

Most of the respondents were on the administrative positions and also pharma Doctors. Approximately $86.2 \%$ were male while $12.1 \%$ were female among the sample. Study shows that majority of the respondents were male. Majority of the respondents were of the ages between 20-30 years with $58.8 \%$ out of which $49.6 \%$ were male and 9.2\% were female. Respondents age between 31-40 years with the percentage of $20.5 \%$, out of which $19.1 \%$ were male and $1.4 \%$ were female. Ages between 51-60 years were $9.3 \%$, out of which $8.5 \%$ were male and $0.7 \%$ were female. Percentages of the respondent between $41-50$ years were 8.5 out of which $7.8 \%$ male and $0.7 \%$ were female. The least age level of sampled respondents was 60 and above with the contribution of $2.8 \%$ and were male.Majority of the respondents i.e. $82.2 \%$ were having education level of graduation out of which $72.3 \%$ were male and $9.9 \%$ were female. The sampled respondents with the qualification of Ms/M.phil were $12 \%$ out of which $10.6 \%$ were male and just two (1.4\%) were female. Respondents having intermediate level of education were very low i.e. $5.6 \%$ out of which $4.9 \%$ were male and $0.7 \%$ were female. 
Distribution of Sampled Respondents by Experience, shows that majority of the respondents were having experience between 1-5 years that is $53.1 \%$ out of which $43.9 \%$ were male and $9.2 \%$ were female. While $24 \%$ of the sampled respondents with the experience of 6-10 years out of which $22.6 \%$ were male and $1.4 \%$ were female. The sampled respondents with the least experience $21-25$ with $2.12 \%$ male.

\subsection{Measures}

All the variables were measured using self-reports. The responses were tapped using a 5-point Likert-scale with anchors ranging from 1- strongly disagree to 5-strongly agree for Organizational justice dimensions(PJ,DJ and IJ) as well for Turnover intention and for Motivation (Extrinsic and Intrinsic motivation) with anchors ranging from 1- very little to 5-strongly .

\subsubsection{Procedural Justice}

Procedural justice was measured by 6-items and 5-point likert scale used by Nadari and Tanova (2010). $\alpha$ reliability for this measure was 0.777 which is consistent with Tabibnia et al. (2008) study. Examples of the items included "Being neutral about decision making, listening to others before decision making and collecting right information related to the topic for decision making."

\subsubsection{Distributive Justice}

Distributive justice was measured by 5-items and 5-point likert scale developed by Niehoff and Moorman (1993). Survey items include: "Fair rewards with regard to responsibilities and Fair rewards with regard to the fulfilled responsibilities". $\alpha$ reliability for this measure was 0.847 which is above the conventional standards.

\subsubsection{Interactional Justice}

Interactional justice was measured by 9-items and 5-points likert scale used by Nadari and Tanova (2010). $\alpha$ reliability for this measure was 0.758. items includeBeing polite and concerned for decisions about my job and Being respectful and careful for decisions about my job.

\subsubsection{Turnover intention}

Turnover intention was measured by 3-items and 5-point likert scale developed by Cammann et al. (1979). The $\alpha$ reliability for this measure was 0.742 . Which is consistent with the reliability reported in past studies (e.g., Tabibnia et al. 2008 and Ponnu and Chuah (2010)). The items include "Often thought of quitting, looking for a new job next year probably and leaving the job next year."

\subsubsection{Intrinsic Motivation}

Intrinsic motivation was measured through 3-items five point likert scale used by Gagne et al. (2010), includes I do this job because I enjoy this work very much, I do this job because I have fun doing my job and I do this job for the moments of pleasure that this job brings to me. The $\alpha$ for this measure was 0.737 which is in conventional standards.

\subsubsection{Extrinsic Motivation}

Extrinsic motivation was measured through 9- items 5-point likert scale used by Gagne et al (2010) in work motivation scale.Alpha reliability for this measure was 0.603 which is slightly low then the conventional standards. Table 1 presents the results for the descriptive statistics, zero-order Pearson correlations, and reliabilities for all the study 
variables. In general, the zero-order correlation results show that all relationships were in the expected directions.

Table 2: Regression analysis for mediating variable (Intrinsic motivation) on relationship between organizational justice and Turnover Intention (Baren and Kenny, 1986).

Step 1: Effect of Organizational Justice on Turnover Intention

Variables

\begin{tabular}{cl}
\multicolumn{1}{c}{$\beta$} & \multicolumn{1}{c}{$\Delta R^{2}$} \\
\hline $\mathrm{PJ}$ & $.440^{* * * *} \quad .45$ \\
$\mathrm{DJ}$ & $.300^{* * *}$ \\
$\mathrm{IJ}$ & $-.581^{\mathrm{ns}}$ \\
\hline $\mathrm{N}=141 ; * * * \mathrm{p}<0.01, * * \mathrm{p}<0.05$
\end{tabular}

Step 2: Effect of Organizational Justice on Intrinsic Motivation (Mediator)

Variables

IM

\begin{tabular}{cl}
\multicolumn{1}{c}{$\beta$} & \multicolumn{1}{c}{$\Delta R^{2}$} \\
\hline $\mathrm{PJ}$ & $.014^{\mathrm{ns}}$ \\
$\mathrm{DJ}$ & $.662^{* * *}$ \\
$\mathrm{IJ}$ & $-.596^{* * *}$ \\
$\mathrm{~N}=141 ; * * * \mathrm{p}<0.01, * * \mathrm{p}<0.05$
\end{tabular}

Step-3 and 4: Effect of organizational justice on turnover intention controlling for Intrinsic Motivation

Variables

TI

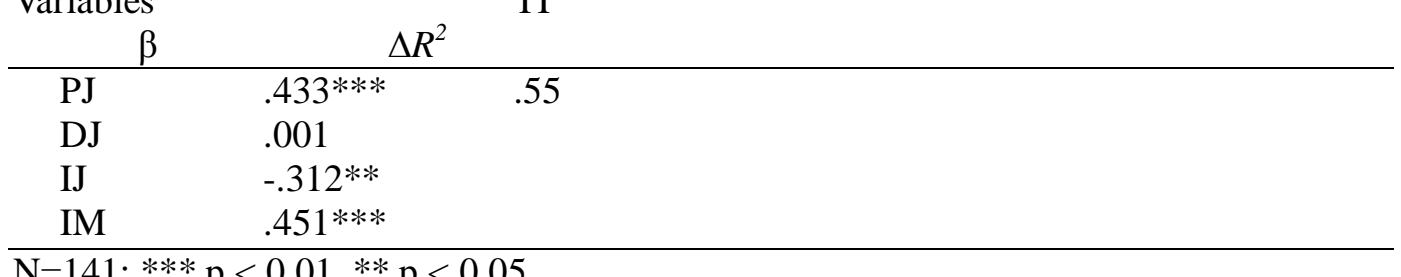

$\mathrm{N}=141 ; * * * \mathrm{p}<0.01, * * \mathrm{p}<0.05$

Table 1 : Mean, standard deviations, correlations and reliabilities

\begin{tabular}{|c|c|c|c|c|c|c|c|c|c|c|c|c|c|}
\hline & Mean & SD & 1 & 2 & 3 & 4 & 5 & 6 & 7 & 8 & 9 & 10 & \\
\hline 1. Gender & 1.12 & 0.326 & - & & & & & & & & & & \\
\hline 2. Age & 1.801 & 1.172 & -0.123 & - & & & & & & & & & \\
\hline $\begin{array}{l}\text { 3. Education } \\
4 .\end{array}$ & 3.063 & 0.417 & -0.004 & $\begin{array}{r}0.076 \\
-\end{array}$ & - & & & & & & & & \\
\hline Experience & 1.914 & 1.406 & -0.133 & 0.006 & -0.051 & - & & & & & & & \\
\hline 5. PJ & & 3.669 & 0.766 & 0.042 & -0.054 & 0.137 & 0.006 & -0.77 & & & & & \\
\hline 6. DJ & & 3.521 & 0.926 & $.196^{*}$ & -0.049 & 0.124 & -0.06 & $.692 * *$ & -0.84 & & & & \\
\hline 7. IJ & & 3.453 & 0.591 & 0.076 & 0.042 & 0.023 & 0.115 & $.257 * *$ & $.275^{* *}$ & -0.75 & & & \\
\hline 8. TI & & 3.196 & 0.976 & 0.097 & 0.007 & 0.074 & -0.08 & $.452^{* *}$ & $.427 * *$ & $-.185^{*}$ & -0.74 & & \\
\hline 9. IM & & 3.271 & 0.95 & 0.085 & 0.008 & 0.142 & $.210^{*}$ & $.363^{* *}$ & $.552^{* * *}$ & $-.190^{*}$ & $.599^{* *}$ & -0.73 & \\
\hline 10. EM & & 3.1 & 0.557 & 0.155 & 0.05 & 0.102 & -0.11 & $.552^{* * *}$ & $.543 * *$ & $.318^{* *}$ & $.275^{* *}$ & $.297 * *$ & -0.6 \\
\hline
\end{tabular}

$N=141 ;$ Cronbach's $\alpha$ presented in parentheses; ${ }^{*} p<0.05 ; * * p<0.01$ 
Table 3: Regression analysis of Extrinsic Motivation (Mediating Variable) on the relationship between Organizational Justice and Turnover Intention.

Step 1 : Effect of Organizational Justice on Turnover Intention)

Variables

TI

\begin{tabular}{cl}
\multicolumn{1}{c}{$\Delta R^{2}$} \\
\hline $\mathrm{PJ}$ & $.440^{* * * *} \quad .45$ \\
$\mathrm{DJ}$ & $.300^{* * *}$ \\
$\mathrm{IJ}$ & $-.581^{\mathrm{ns}}$ \\
\hline $\mathrm{N}=141 ; * * * \mathrm{p}<0.01, * * \mathrm{p}<0.05$
\end{tabular}

Step 2: Effect of Organizational Justice on Extrinsic Motivation (Mediator)

Variables EM

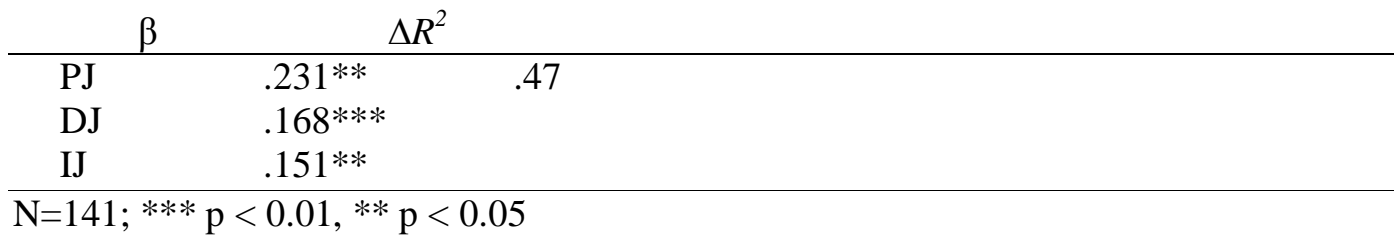

Step-3 and 4: Effect of organizational justice on turnover intention controlling for Extrinsic Motivation

\begin{tabular}{cl}
\multicolumn{1}{c}{$\begin{array}{c}\text { Variables } \\
\beta\end{array}$} & \multicolumn{1}{c}{ TI } \\
\multicolumn{1}{c}{$\Delta R^{2}$} \\
\hline $\mathrm{DJ}$ & $.280^{* * * *}$ \\
$\mathrm{IJ}$ & $-.599 * * *$ \\
$\mathrm{EM}$ & $.118^{\text {ns }}$ \\
\hline $\mathrm{N}=141 ; * * * \mathrm{p}<0.01, * * \mathrm{p}<0.05$
\end{tabular}

Theoretical frame work

Theoretical framework of organizational justice dimensions (PJ, DJ and IJ) in relation with Turnover Intention was the main focus of this study by taking organizational justice as independent variable and TI as dependent variables used by Nadari and Tanova (2010). In their studies regarding an investigation of the role of justice in TI, JS, and OCB in hospitality industry in addition the determinants of employee motivation i.e. Intrinsic Motivation and Extrinsic Motivation was considered as mediating variables ${ }^{6}$. The mediating variable Intrinsic Motivation and Extrinsic Motivation was taken from (Warwer, 2013) as mediating variable.

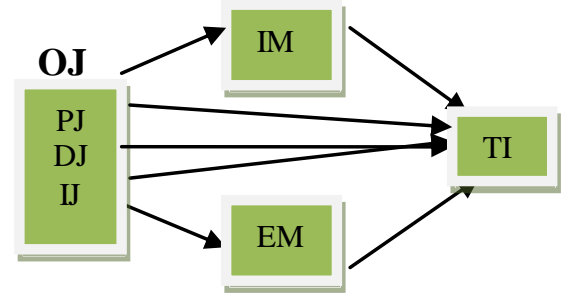

Figure 1: Theoretical framework of Organizational Justice (PJ, DJ and IJ) and Turnover Intention 


\section{Data Analysis}

The data collected from the respondents were put in the Statistical Package for Social Sciences (SPSS), to study the employee perception regarding different attributes of study. Data were examined using descriptive statistics, i.e. frequencies and percentages. Coefficient reliability (Chronbach Alpha) was proposed for scales measuring, PJ, DJ, IJ, TI, IM and EM. Pearson Correlations were also founded for each pair of variables and to determine the contribution; Regression analysis were performed to find the relationship between organizational justice dimensions (PJ, DJ and IJ) and TI directly and also to find mediation (Intrinsic and Extrinsic motivation) on relation between organizational justice and turnover intention. To determine the relative contribution, regression models were used to analyze those effects by using ordinary least square (OLS) method. Models given below address the hypotheses $(1,2,3)$ given in the introduction section. Hypothesis 1, 2, and 3 are addressed by 2,3 and 4 respectively.

$$
\begin{aligned}
& \mathrm{TI}=\beta_{0}+\beta_{1} \mathrm{PJ}+\varepsilon \\
& \mathrm{TI}=\beta_{0}+\beta_{1} \mathrm{DJ}+\varepsilon \\
& \mathrm{TI}=\beta_{0}+\beta_{1} \mathrm{IJ}+\varepsilon
\end{aligned}
$$

The regression model mentioned in equations (2, 3 and 4) used to test the effect of PJ, DJ and IJ on TI respectively. Accordingly to find the effect of mediating variables' (Intrinsic and Extrinsic motivation), four steps formulated by Baren and kenney's (1986) model as shown in the figure below for rest of the other hypotheses i.e. 4 and 5.

1)

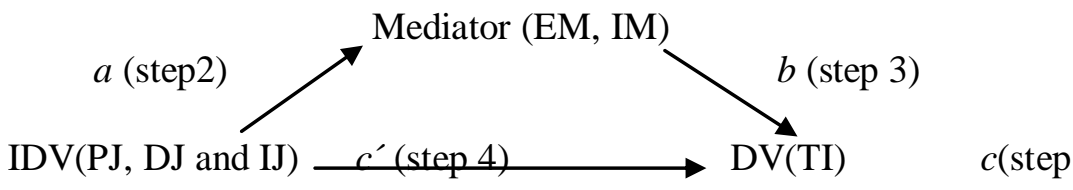

Figure 2: Adopted from Baron and Kenny (1986)

According to Baron and Kenny's (1986) econometric models were adapted to understand with ease for separate hypothesis as under.

\section{Hypothesis \# 4}

Step 1: $\mathrm{TI}=\mathrm{c}_{0}+\mathrm{c}_{1} \mathrm{PJ}+\mathrm{c}_{2} \mathrm{DJ}+\mathrm{c}_{3} \mathrm{IJ}+\mathrm{e}_{1}$

Step2: $\quad I M=a_{0}+a_{1} P J+a_{2} D J+a_{3} I J+e_{2}$

Step3 \& 4:TI $=\mathrm{c}_{0}{ }_{0}+\mathrm{c}^{\prime}{ }_{1} \mathrm{PJ}+\mathrm{c}_{2}{ }_{2} \mathrm{DJ}+\mathrm{c}_{3} \mathrm{IJ}+\mathrm{bIM}+\mathrm{e}_{3}$

\section{Hypothesis \# 5}

Step 1: $\mathrm{TI}=\mathrm{c}_{0}+\mathrm{c}_{1} \mathrm{PJ}+\mathrm{c}_{2} \mathrm{DJ}+\mathrm{c}_{3} \mathrm{IJ}+\mathrm{e}_{1}$

Step2: $\quad I M=a_{0}+a_{1} P J+a_{2} D J+a_{3} I J+e_{2}$

Step3 \& 4:TI $=\mathrm{c}^{\prime}{ }_{0}+\mathrm{c}^{\prime}{ }_{1} \mathrm{PJ}+\mathrm{c}_{2} \mathrm{DJ}+\mathrm{c}_{3}{ }_{3} \mathrm{IJ}+\mathrm{bEM}+\mathrm{e}_{3}$

Some of the tests as used by Kenny (2012), Shah et al. (2013) were also used. The Baron and Kenny`s (1986) model doesn't show us the statistical significance rather than showing us the zero and non zero coefficients of the models like In case $c \neq 0$ in step $1, \mathrm{a} \neq 0$ in step $2, \mathrm{~b} \neq 0$ in step 3 and $\mathrm{c}^{\prime}=0$ in step 4 , there would be complete mediation; otherwise, in case of $c^{\prime} \neq 0$ in step 4, there would be partial mediation. Kenny (2012) procedure should be applied because the old version of meditational analysis does not signify that there is such statistical significance in these four step model proposed by 
Baren and Kenny (1986). Kenny carried out research and proposed some of the changes to know the exact analysis and procedure to be adopted and give you significant resultsregarding mediation and stated that if we see that Baren and Kenny (1986) steps are at best at starting point at meditational analysis. More contemporary analysis focus on the indirect effect secondly stated that those meditational steps are in terms of zeros and non zeros coefficient further stated that most of the contemporary analysis belief that while finding the meditation effect the essential steps for mediation are 2 and 3 rather than 1 and 4. While establishing the mediation according to Kenny (2012) here are some computation and tests which are followed in this study. Those computations and tests are described below.

\section{(i) Establishing of Direct, Indirect and Total effect}

Through formulas and computation we will be known to find out the direct, indirect and total effect and is worthy then estimation of coefficients (c,a,b and $\left.c^{\prime}\right)$. This computation is done through simple formulas by putting the values of coefficients and also to find the percentages of direct and indirect effect. Formulas are mentioned on next page.

$$
\begin{gathered}
\text { Total effect }=\text { Direct effect }+ \text { Indirect effect } \\
\qquad c=c^{\prime}+a b
\end{gathered}
$$

by finding the total effect put the values of $c^{\prime}$, $a$ and $b$ in the formula above and then the total effect is decomposed into direct and indirect effect using the formulas given under

$$
\begin{array}{ll}
\text { Direct effect }(\%)=\left(c^{\prime} / \mathrm{c}\right) \times 100 & \text { (II) } \\
\text { Indirect effect }(\%)=(\mathrm{ab} / \mathrm{c}) \times 100 & \text { (III) }
\end{array}
$$

The percentage gotten from these computations will signifies the percentage of direct effect and indirect (mediation) effect by finding those percentages if significant we will go for some tests and Those tests will show the mediation and their significance of the results as under:

\section{(ii) Testing a and b separately}

This test is used to check the significance of the path $a$ and $b$ in the conceptual model of barren and Kenny (1986). If the paths ( $a$ and $b$ ) shows that the p-value is less than 0.001 then will be concluded that there is meditational effect and also regression coefficients as well are positive. If not significant $(p>0.001)$ then there will be no mediation.

\section{(iii) Using Sobel $z$ test}

Sobel $z$ test was also applied by using formula that is

$$
Z_{a b}=a b / s_{a b}
$$

This followed Z-distribution, that is, $a b / s_{a b}$ will fall within \pm 1.96 interval for an $a b=0$ otherwise, it will fall outside of the stated interval. Where $s_{a b}$ has to be computed, using formula:

$$
s_{a b}= \pm \sqrt{ }\left(a^{2} s_{b}^{2}+b^{2} s_{a}^{2}\right)
$$

Where $s_{a}$ and $s_{b}$ are the standard errors of $a$ (coefficient of path- $a$ ) and $b$ (coefficient of path- $b$ ), respectively. Appendix provides complete computation done by using formula given above. Statistics $Z_{a b}$, computed for meditational effect $(a b)$ of mediating variables (Intrinsic and extrinsic motivation) and other variables of interest if fall within the \pm 1.96 interval (Appendix II). Then there will be mediation if not then there is no mediation 
effect and accordingly the hypothesis will be accepted or rejected.

\section{Discussion and Conclusion}

Main objective of the study was to find the relationship of independent variables (PJ, DJ and IJ) with dependent variable (TI) and also to find the meditational effect of employee motivation dimensions (IM and EM) on the relationship between Organizational Justice facets (PJ, DJ and IJ) and Turnover Intention of employees working in pharmaceutical industries located in Hayatabad Industrial Estate, Peshawar. Data collected from 141 employees was analyzed using correlation analysis and regression analysis. Moreover, MAS was also calculated and alpha reliabilities were checked. The response rate was observed $73 \%$ and about $88 \%$ were male and $12 \%$ were female. Majority of the sampled respondents (58.8\%) having age between 20-30 and the majority of the respondents $(82.2 \%)$ were graduates. Majority $(53.1 \%)$ of the sampled respondents were having experience ranging 1 to 5 years. Responses on the elements of all six constructs (TI, IM, EM, PJ, DJ and IJ) were tested for reliability; Overall Cronbach's alpha equal to 0.860 . The Pearson correlations or degrees of associations between TI and PJ, DJ, IM and EM, were estimated at 0.452, 0.427, 0.599 and 0.275 respectively. These correlations were found not too strong, but these were statistically highly significant $(\mathrm{p}<0.01)$ except $\mathrm{IJ}$ that is -0.185 with insignificant $\mathrm{p}$-value (0.028). The Pearson correlations between IM and PJ, DJ and IJ were found at 0.448, 0.665 , and 0.317 respectively while the correlation between EM and PJ, DJ and IJ were found at $.545, .543$ and .318 respectively. The reliabilities were also very good. Through regression analysis relationship between PJ and TI were found significant for which pvalue is 0.000 . The relationship between DJ and TI is also significant for which p-value is 0.000 . The relationship of IJ and TI is insignificant for which p-value is .024.

For mediation analysis we used Baren and Kenny (1986) four step model to find the meditational effects of Intrinsic and Extrinsic motivation and we found in the study that there is a meditational effect on relationship between Organizational Justice (OJ) and Turnover Intention (TI). This study also comprises of Kenny (2012) procedure for finding the significance of mediation effect. The values are computed to find wither there is any direct $(\%)$ and indirect effect $(\%)$ and there is an effect. Secondly applied some tests for significance of coefficients of indirect effect (Page-42 testing a and b separately) and the values are positive and significant. Lastly we done computation for sobel $\mathrm{z}$ test according to Kenny (2012) if the value of $\mathrm{z}_{\mathrm{ab}}$ lies within \pm 1.96 confidence interval the mediation effect will be significant and if lies beyond \pm 1.96 confidence interval then will be insignificant (Table 3.26 and 4.27). So it is concluded that EM mediates the relation between organizational justice facets (PJ and DJ) and turnover intention. Except IJ which is inconsistent variable.

\subsection{Conclusion}

The research finding showed that there is positive and highly significant relationship between two of the organizational justice facets i.e. procedural justice (PJ) and distributive justice (DJ) with the turnover intention (TI). This showed that the employees working in those organizations, feels that if there is justice in the procedures and the reward distributions they may have no intention towards turnover. However, the relationship between interactional justice (IJ) and TI is negative and insignificant showed 
that there is no such interaction of the supervisor and subordinate. This study suggests some guidelines to help top management in realizing how to retain their employees by providing just environment at the work place. The study helps in foreseeing that when Perceive fairness in treating employees in terms of outcomes and procedures are there then the employees will remain in the current organization and have no intentions to opt for another substitute. Considering these constructs (PJ, DJ and IJ), the likelihood of quitting or leaving of employees can slowly be reduced. This study also concludes that there is sufficient/significant meditational effect by the constructs (IM and EM) on the relationship between the facets of organizational justice (PJ and DJ) and turnover intention, Except the meditational analysis in both IM and EM on the relationship between Interactional Justice and Turnover Intention, whereas the relationship is inconsistent because coefficient of correlation was negative. By implementing those kinds of studies, the organizations embrace profitability and popularity in long run among the competitors in the market.

\section{References}

Adams, J. S. (1965). Inequity in social exchange. Advances in experimental social psychology, 2(267-299).

Allen, N. J., \& Meyer, J. P. (1996). Affective, continuance, and normative commitment to the organization: An examination of construct validity. Journal of vocational behavior, 49(3), 252-276.

Alexander, S., \& Ruderman, M. (1987). The role of procedural and distributive justice in organizational behavior. Social Justice Research, 1(2), 177-198.

Blader, S. L., \& T. R. Tyler (2005). How can theories of organizational justice explain the impact of fairness? In Colquitt, J. A., Greenberg, J., \& Zapata-Phelan, C. P. (Eds.). What is organizational justice? A historical overview. Handbook of organizational justice, 1, 3-58.

Bretz, R. D., Boudreau, J. W., \& Judge, T. A. (1994). Job search behavior of employed managers. Personnel Psychology, 47(2), 275-301.

Fatt, C. K., Khin, E. W. S., \& Heng, T. N. (2010). The impact of organizational justice on employee's job satisfaction: The Malaysian Companies perspectives. American Journal of Economics and Business Administration, 2(1), 56.

Cropanzano, R., Rupp, D. E., \& Byrne, Z. S. (2003). The relationship of emotional exhaustion to work attitudes, job performance, and organizational citizenship behaviors. Journal of Applied Psychology, 88(1), 160.

Cropanzano, R., \& Greenberg, J. (1997). Progress in organizational justice: Tunneling through the maze. International review of industrial and organizational psychology, 12, 317-372.

Cruceru, R., \& Macarescu, C. (2009). Interactional Justice: The Link Between Employee Retention And Employment Lawsuits. Romanian Economic and Business Review, 4(4), 95.

Cochran, W. G. (1977). Sampling techniques-3.

Coetzee, M. (2005). The fairness of affirmative action: An organizational justice perspective (Doctoral dissertation, University of Pretoria). 
Cohen-Charash, Y., \& Spector, P. E. (2001). The role of justice in organizations: A metaanalysis. Organizational behavior and human decision processes, 86(2), 278321.

Colquitt, J. A., Conlon, D. E., Wesson, M. J., Porter, C. O., \& Ng, K. Y. (2001). Justice at the millennium: a meta-analytic review of 25 years of organizational justice research. Journal of applied psychology, 86(3), 425.

Dysvik, A., \& Kuvaas, B. (2010). Exploring the relative and combined influence of mastery-approach goals and work intrinsic motivation on employee turnover intention. Personnel review, 39(5), 622-638.

Emerson, R. M. (1976). Social exchange theory. Annual review of sociology, 335-362.

Folger, R., \& Konovsky, M. A. (1989). Effects of procedural and distributive justice on reactions to pay raise decisions. Academy of Management journal, 32(1), 115130.

Gagné, M., Forest, J., Gilbert, M. H., Aubé, C., Morin, E., \& Malorni, A. (2010). The Motivation at Work Scale: Validation evidence in two languages. Educational and psychological measurement, 70(4), 628-646.

Greenberg, J. (1987). A taxonomy of organizational justice theories. Academy of Management review, 12(1), 9-22.

Greenberg, J. (1990). Organizational justice: Yesterday, today, and tomorrow. Journal of management, 16(2), 399-432.

Kacmar, K. M., Bozeman, D. P., Carlson, D. S., \& Anthony, W. P. (1999). An examination of the perceptions of organizational politics model: Replication and extension. Human relations, 52(3), 383-416.

Katzell, R. A., \& Thompson. D. E. (1990). Work motivation: Theory and practice. American Psychologist, 45, 144-153.

Keaveney, S. M., \& Nelson, J. E. (1993). Coping with organizational role stress: Intrinsic motivational orientation, perceived role benefits, and psychological withdrawal. Journal of the Academy of Marketing Science, 21(2), 113-124.

Khan, K., Abbas, M., Gul, A., \& Raja, U. (2015). Organizational justice and job outcomes: Moderating role of Islamic Work Ethic. Journal of Business Ethics, 126(2), 235-246.

Kenny, D. A. (2012). Mediation; available on: davidakenny.net, in Shah, A., Hashmi, S. H., \& Chishti, A. F. Much has changed since Baron and Kenny's (1986) classic paper: let us learn what Kenny's (2012) con-temporary mediation analysis prescribes. Editorial Board, 58.

Lee, H. R. (2000). An empirical study of organizational justice as a mediator of the relationships among leader-member exchange and job satisfaction, organizational commitment, and turnover intentions in the lodging industry (Doctoral dissertation, Virginia Polytechnic Institute and State University).

Leventhal, G. S. (1980). What should be done with equity theory? (pp. 27-55). Springer US.

Martin, L. L., Ward, D. W., Achee, J. W., \& Wyer, R. S. (1993). Mood as input: People have to interpret the motivational implications of their moods. Journal of Personality and Social Psychology, 64(3), 317. 
Masterson, S. S., \& Taylor, M. S. (1996). The broadening of procedural justice: Should interactional and procedural components be separate theories. In annual meeting of the Academy of Management, Cincinnati.

McFarlin, D. B., \& Sweeney, P. D. (1992). Research notes. Distributive and procedural justice as predictors of satisfaction with personal and organizational outcomes. Academy of management Journal, 35(3), 626-637.

McGregor, D. (1960). The human side of enterprise. New York, 21(166.1960).

Mathieu, J. E., \& Zajac, D. M. (1990). A review and meta-analysis of the antecedents, correlates, and consequences of organizational commitment. Psychological bulletin, 108(2), 171.

Moorman, R. H. (1991). Relationship between organizational justice and organizational citizenship behaviors: Do fairness perceptions influence employee citizenship? Journal of applied psychology, 76(6), 845.

Nadiri, H., \& Tanova, C. (2010). An investigation of the role of justice in turnover intentions, job satisfaction, and organizational citizenship behavior in hospitality industry. International journal of hospitality management, 29(1), 33-41.

Nelson, R., Howden, M., \& Smith, M. S. (2008). Using adaptive governance to rethink the way science supports Australian drought policy. Environmental Science \& Policy, 11(7), 588-601.

Niehoff, B. P., \& Moorman, R. H. (1993). Justice as a mediator of the relationship between methods of monitoring and organizational citizenship behavior. Academy of Management journal, 36(3), 527-556.

Owolabi, A. B. (2012). Effect of organizational justice and organizational environment on turn-over intention of health workers in Ekiti state, Nigeria. Research in World Economy, 3(1), 28.

Poon, J. M. (2012). Distributive Justice, Procedural Justice, Affective Commitment, and Turnover Intention: A Mediation-Moderation Framework1. Journal of Applied Social Psychology, 42(6), 1505-1532.

Ponnu, C. H., \& Chuah, C. C. (2010). Organizational commitment, organizational justice and employee turnover in Malaysia. African Journal of Business Management, 4(13), 2676.

Shah, A., Hashmi, S. H., \& Chishti, A. F. Much has changed since Baron and Kenny's (1986) classic paper: let us learn what Kenny's (2012) con-temporary mediation analysis prescribes. Editorial Board, 58.

Tabibnia, G., Satpute, A. B., \& Lieberman, M. D. (2008). The sunny side of fairness preference for fairness activates reward circuitry (and disregarding unfairness activates self-control circuitry). Psychological Science, 19(4), 339-347.

Tett, R. P., \& Meyer, J. P. (1993). Job satisfaction, organizational commitment, turnover intention, and turnover: path analyses based on meta-analytic findings. Personnel psychology, 46(2), 259-293.

Thibaut, J. \& Walker. J. (1975).Procedural Justice. Hillsdale, NJ: Lawrence Erlbaum

Thomas, J. W., and J. R. Mergendoller. 2000. Managing project-based learning: Principles from the field. Paper presented at the Annual Meeting of the American Educational Research Association, New Orleans. 
Tyagi, P. K. (1990). Inequities in organizations, salesperson motivation and job satisfaction. International Journal of Research in Marketing, 7(2), 135-148.

Vroom, V. H. (1964). Work and motivation. New York: John Willey \& Sons. Inc. VroomWork and Motivation1964.

Warwer. O, Onesimus, Djumilah, Armanu \& Mintarti. (2013). Intrinsic and Extrinsic Motivation Mediate Self-Leadership Focused Behavioral Strategies and Performance Outcome, International Journal of Management, 5(4), 191 - 203

Zapata-Phelan, C. P., Colquitt, J. A., Scott, B. A., \& Livingston, B. (2009). Procedural justice, interactional justice, and task performance: The mediating role of intrinsic motivation. Organizational Behavior and Human Decision Processes, 108(1), 93-105. 